\title{
Risk Factors for Bud Perennation of Podosphaera macularis on Hop
}

\author{
David H. Gent, ${ }^{\dagger}$ Walter F. Mahaffee, William W. Turechek, Cynthia M. Ocamb, Megan C. Twomey, \\ Joanna L. Woods, and Claudia Probst
}

First author: United States Department of Agriculture-Agricultural Research Service (USDA-ARS), Forage Seed and Cereal Research Unit, Corvallis, OR 97331; second author: USDA-ARS, Horticultural Crops Research Unit, Corvallis, OR 97330; third author: USDA-ARS, U.S. Horticultural Research Unit, Fort Pierce, FL 34945; fourth, fifth, and sixth authors: Department of Botany and Plant Pathology, Oregon State University, Corvallis 97331; and seventh author: Department of Plant Pathology, Washington State University Irrigated Agriculture Research and Extension Center, Prosser 99350.

Accepted for publication 11 July 2018.

\begin{abstract}
The hop powdery mildew fungus Podosphaera macularis persists from season to season in the Pacific Northwestern United States through infection of crown buds because only one of the mating types needed to produce the ascigerous stage is presently found in this region. Bud infection and successful overwintering of the fungus leads to the emergence of heavily infected shoots in early spring (termed flag shoots). Historical data of flag shoot occurrence and incidence in Oregon and Washington State during 2000 to 2017 were analyzed to identify their association with the incidence of powdery mildew, growers' use of fungicides, autumn and winter temperature, and other production factors. During this period, flag shoots were found on $0.05 \%$ of plants evaluated in Oregon and $0.57 \%$ in Washington. In Oregon, the incidence of powdery mildew on leaves was most severe and the number of fungicide applications made by growers greatest in yards where flag shoots were found in spring. Similarly, the incidence of plants with powdery mildew in Washington was significantly associated with the number of flag shoots present in early spring, although the number of fungicide applications made was independent of flag shoot occurrence. The occurrence of flag shoots was associated with prior occurrence of flag shoots in a yard, the incidence of foliar powdery mildew in the previous year, grower pruning method, and, in Washington, winter temperature. A census of hop yards in the eastern extent of the

Oregon production region during 2014 to 2017 found flag shoots in 27 of 489 yards evaluated. In yards without flag shoots, 338 yards $(73.2 \%)$ were chemically pruning or not pruned, whereas the remaining $124(26.8 \%)$ were mechanically pruned. Of the 27 yards with flag shoots, 22 were either chemically pruned or not pruned and 4 were mechanically pruned in mid-April, well after the initial emergence of flag shoots. The prevalence of yards with flag shoots also was related to thoroughness of pruning in spring $(8.1 \%$ of yards with incomplete pruning versus $1.9 \%$ of yards with thorough pruning). A Bayesian logistic regression model was fit to the data from the intensively assessed yards in Oregon, with binary risk factors for occurrence of a flag shoot in the previous year, occurrence of foliar mildew in the previous year, and thoroughness of pruning in spring. The model indicated that the median and $95 \%$ highest posterior density interval of the probability of flag shoot occurrence was $0.0008(0.0000$ to 0.0053$)$ when a yard had no risk factors but risk increased to 0.0065 (0.0000 to 0.0283$)$ to $0.43(0.175$ to 0.709$)$ when one to all three of the risk factors were present. The entirety of this research indicates that $P$. macularis appears to persist in a subset of chronically affected hop yards, particularly yards where spring pruning is conducted poorly. Targeted management of the disease in a subset of fields most at risk for producing flag shoots could potentially influence powdery mildew development regionwide.
\end{abstract}

Initial epidemic conditions may have profound impacts on disease progression and pathogen dispersal for organisms capable of long-distance dispersal (Mundt and Sackett 2012, 2013; Ojiambo et al. 2017). Early intervention to reduce primary inoculum is important for limiting overall severity and spatial extent of epidemics (Severns et al. 2014, 2015). Management of primary inoculum is also critically important for polycyclic diseases when such inoculum provides an ongoing source of new infections (Filho et al. 2016).

These concepts are especially important for obligate parasites limited by primary inoculum dose. In the case of powdery mildew fungi, perennation (the ability to survive from one season to another) may involve formation of ascocarps on living host tissue that later senesces and dies or survival in or on living host tissue as

†Corresponding author: David H. Gent; E-mail: Dave.Gent@USDA.gov

Funding: Financial support was provided by USDA-ARS Current Research Information System 2072-21000-051-00D, Washington State University, the Hop Research Council, Washington State Commission on Pesticide Registrations, and Washington State Department of Agriculture Specialty Crops Research Block Grant program (K1508).

This article is in the public domain and not copyrightable. It may be freely reprinted with customary crediting of the source. The American Phytopathological Society, 2019. vegetative mycelium (Jarvis et al. 2012). In many powdery mildew pathosystems, mycelial invasion of buds is common and enables the fungus to persist in a quiescent state within dormant buds (Jarvis et al. 2012). Bud infection may lead to the development of flag shoots, which are shoots that emerge partly to entirely colonized by the pathogen.

Bud perennation is the primary means of overwintering of the hop powdery mildew fungus Podosphaera macularis in the U.S. Pacific Northwest. P. macularis is heterothallic and chasmothecia of the fungus are produced and broadly dispersed where powdery mildew occurs in eastern North America and Europe (Wolfenbarger et al. 2015). However, the ascigerous stage is not known to occur in the Pacific Northwestern United States (Gent et al. 2006; Klein 1998; Ocamb et al. 1999; Turechek et al. 2001). In this region, at present, only the MAT1-1 mating type has been found and existing quarantine measures on planting material are intended to prevent the introduction of the second mating type (Wolfenbarger et al. 2015). Consequently, primary inoculum must originate from flag shoots within a yard, disperse from other yards, or be introduced on planting material.

The overwintering biology of $P$. macularis is largely unexplored, in part because flag shoots tend to be relatively rare on hop and are difficult to study without long-term data sets. Previous surveys of commercial hop yards found flag shoots on approximately $0.69 \%$ of hop plants in Washington and $0.02 \%$ of plants in Oregon (Gent et al. 
2008). Although flag shoot occurrence is a relatively rare event, this level of overwintering is sufficient to initiate outbreaks of powdery mildew that become epidemic annually in both states. The frequency of flag shoots is known to be associated with spring pruning practices, which reduce or eliminate the first flush of stems that emerge in late winter and early spring (Gent et al. 2012, 2018; Turechek et al. 2001). The thoroughness of spring pruning is correlated with the overall seasonal severity of powdery mildew on leaves and, ultimately, cones, in part due to elimination of primary inoculum (Gent et al. 2012; Turechek et al. 2001). In England, Royle (1978) noted that outbreaks of powdery mildew began earlier in the season when mechanical pruning was replaced with chemical desiccation of shoots. Emergence of hop shoots and flag shoots is asynchronous, and some late flag shoots may emerge after the initial chemical desiccation of shoots and, thus, survive this practice (Gent et al. 2018).

Multiple lines of evidence indicate that bud infection leading to flag shoots occurs after bloom (July in the northern hemisphere). In England, Liyanage and Royle (1976) found that flag shoot development was associated with infection of buds during or after July of the preceding year. This is coincident with the period when overwintering crown buds are initiated and mature (Gent et al. 2018). Susceptibility to powdery mildew is maximal on juvenile buds, and susceptibility decreases markedly with bud maturation in late September (Gent et al. 2018). In spring, the number of flag shoots produced generally is related to when plants were inoculated during the previous season, with an overall tendency for earlier infection to lead to more flag shoots.

Given that the level of overwintering of $P$. macularis is variable among fields, years, and production regions, and primary inoculum dose appears to be a primary determinant of epidemic severity, there is motivation to understand when and where flag shoots are most likely to occur. Identification of production situations at most risk for flag shoot development could allow for a more targeted management of the disease in a subset of yards to disrupt overwintering. With this motivation, the specific objectives of this work were to (i) quantify the association between flag shoots and production factors and (ii) formalize risk factors for flag shoots occurrence into a model to estimate the likelihood of flag shoot occurrence.

\section{MATERIALS AND METHODS}

Field sites and general description of data sets. Measurements of powdery mildew and associated risk factors were obtained from sampling conducted in commercial hop yards in Washington and Oregon during each year from 2000 to 2017. Yards in Washington were located in the three primary production regions, dubbed the Yakima Indian Reservation, Moxee, and the Lower Valley region of the Yakima Valley, as described by Barth (1994). Oregon hop yards were all located in Marion County. The incidence of powdery mildew varies between these regions due to a combination of climate, cultivars produced, and grower production practices (Turechek et al. 2001; Wolfenbarger et al. 2016). Disease pressure generally is greatest near the Yakima Indian Reservation, followed by Moxee, the Lower Valley region, and Oregon. The Yakima Valley has a cold, semiarid climate with a Mediterranean precipitation pattern, whereas the hop production regions in western Oregon are dominated by a west coast marine climate with cool, wet winters and warm, dry summers.

Two data sets were collected from these sites. The first was a long-term data set developed from annual surveys of commercial hop yards during 2000 to 2017 in both Oregon and Washington. The temporal and spatial extent of this data allowed for identification of potential risk factors for flag shoot occurrence that may differ between the contrasting climates of the two states (e.g., winter temperature) and other production factors. The hop yards included in the long-term data set were planted to yards relatively susceptible to powdery mildew (Gent et al. 2015; Henning et al. 2009), as noted below. The second data set was an intensive assessment of flag shoots conducted during 2014 to 2017 in Oregon. In this second data set, a census of all hop yards on a group of farms, independent of the cultivar susceptibility to powdery mildew, was conducted to more fully capture spatial aspects of flag shoot development at the mesoscale level. A full description of the data sets is presented below.

Data analysis utilized both data sets in an iterative manner. The general approach was to utilize the long-term data set to identify and describe potential risk factors associated with flag shoots occurrence. These factors were further explored and confirmed as associated with flag shoots in the intensively assessed Oregon data set, then formulated into a logistic regression model to express formally risk factors for flag shoot occurrence. Therefore, the intensively assessed Oregon data set served as means of verification of the risk factors identified in the long-term data set.

Flag shoot assessments. Long-term data set. The yards included in the long-term data set were not selected based on a probability sample but, rather, reflected an amalgamation of yards included in annual surveys and data from other experiments where the incidence of flag shoots were measured. The yards sampled reflected a bias toward cultivars that were susceptible to powdery mildew at the time of the assessments, important cultivars for each state, or cultivars utilized for other studies. Therefore, this data set cannot be assured of external validity (that is, may not be generalizable to the entire population of yards in Oregon or Washington) but is useful for identification of potential risk factors for flag shoots in the second iteration of the analysis as described below.

In total, 355 yards were evaluated for powdery mildew flag shoots during 2000 to 2017, representing 131 observations from Oregon and 224 from Washington (Table 1). The cultivars evaluated in Oregon were Centennial (4 yards), Glacier (3 yards), Horizon (2 yards), Liberty (1 yard), Magnum (4 yards), Nugget (4 yards), Perle (13 yards), Sterling (1 yard), and Willamette (99 yards). In Washington, yards evaluated were Apollo (10 yards), Bravo (18 yards), Cascade (4 yards), Chelan (1 yard), Columbus/Tomahawk/ Zeus (165 yards), Galena (3 yards), Nugget (16 yards), Warrior (1 yard), and Willamette (6 yards). The number of yards assessed varied by year, averaging 7.7 per year (standard deviation 4.3) in Oregon and 12.4 per year (standard deviation 8.8) in Washington. Yards ranged in size from approximately 1 to 20 ha.

The number and incidence of flag shoots was assessed using a modification of the methods described by Turechek et al. (2001) and Turechek and Mahaffee (2004). Each yard was divided into strata of 20 rows, and at least two strata per yard were sampled by evaluating 100 to 200 hills (referred to hereafter as plants) in a transect (row). Sampling conducted during 1999 to 2005 involved 100 plants per transect and, thereafter, at least 200 plants per transect. In cases when a row contained fewer than the desired number of plants, an additional transect was selected and sampling continued until at least the desired number of plants were sampled.

Sampling was conducted during late March to mid-April, just before spring pruning practices are typically conducted in hop yards (Gent et al. 2012). Each plant was inspected for the presence of flag shoots, and the number of plants with flag shoots and the total number of flag shoots was recorded. An infected shoot was deemed a flag shoot if coalescent powdery mildew colonies were found entirely or primarily on the stem, only at each node on stipules, or mostly to entirely on a single leaf, as depicted by Mahaffee et al. (2009).

Intensive assessment of flag shoots in Oregon. The more eastern hop production regions in Marion County chronically tend to have more powdery mildew than the western production regions, for unknown reasons. Thus, this region was targeted for intensive assessments of flag shoots during 2014 to 2017. In each year, every commercial hop yard on all farms ( 8 to 10 farms, year dependent) was 
assessed for flag shoots during April and again in May. This was a total of 107 yards in 2014, 123 in 2015, 125 in 2016, and 134 in 2017. The cultivars evaluated each year are detailed in Table 2. Powdery mildew susceptibility varies substantially among these cultivars (Gent et al. 2015; Henning et al. 2009), sometimes depending on race-specific resistance (Gent et al. 2017; Wolfenbarger et al. 2016). Sampling was similar to the methods described previously for the long-term data set, with two exceptions. Sampling was conducted during both April and May to account for potential asynchrony in flag shoot emergence (Gent et al. 2018). Additionally, there were 50 plants sampled per transect in 2014, whereas 100 to 200 plants were sampled per transect during 2015 to 2017.

Powdery mildew assessments on leaves. Long-term data set. In the long-term data set, the incidence of plants with powdery mildew was assessed in a subset of 268 yards (117 in Oregon; 151 in Washington). Leaf disease sampling followed the cluster sampling methods described by Turechek and Mahaffee (2004) and Gent et al. (2007). Yards were stratified as described for the flag shoot assessments and, in each of two rows, 10 leaves were selected arbitrarily from the first 75 to 100 plants (the sampling units) along the transect, and each leaf was rated for presence or absence of powdery mildew. The incidence of plants with powdery mildew within the yard was then calculated as described by Turechek and Mahaffee (2004).

Disease incidence was assessed every 7 to 21 days throughout the season beginning in late May to early June and continuing until late August. When at least four disease evaluations were conducted over time, the relative area under the disease progress curve (RAUDPC), based on the incidence of plants with powdery mildew, was calculated using the time-standardized version of the trapezoidal method (Madden et al. 2007). In 66 instances, it was not possible to collect sufficient disease data over time to calculate RAUDPC. Therefore, the incidence of leaves with powdery mildew in late June to July was used instead of RAUDPC in subsequent analyses, as described below. Typically, late June to early July is when the incidence of leaves with powdery mildew is maximal (Probst et al. 2016) because leaf development essentially ceases after the summer solstice, when plants bloom (Thomas 1967), and existing leaves develop ontogenic resistance (Turechek et al. 2001). Disease incidence at this time period was correlated with RAUDPC (Pearson's correlation coefficient $r=$ $0.70[P<0.0001]$ and $r=0.96[P<0.0001]$ in Washington and Oregon, respectively) and, thus, was deemed a reasonable proxy for seasonlong disease incidence data.
Intensive assessment of flag shoots in Oregon. In the second data set from intensively assessed yards in Oregon, the incidence of plants with powdery mildew was assessed monthly during April to July. Again, each yard was divided into strata of 20 rows, and at least two strata per yard were sampled by evaluating all leaves visible

TABLE 2. Cultivars evaluated for flag shoots during an intensive sampling of all hop yards in the eastern extent of the hop production region in Marion County, OR during 2014 to 2017

\begin{tabular}{|c|c|c|c|c|}
\hline \multirow[b]{2}{*}{ Cultivar } & \multicolumn{4}{|c|}{ Number of yards evaluated } \\
\hline & 2014 & 2015 & 2016 & 2017 \\
\hline Amarillo & $\ldots$ & $\ldots$ & 1 & 1 \\
\hline Apollo & 1 & 1 & 1 & 1 \\
\hline Bravo & 1 & 1 & 1 & 1 \\
\hline Brewers Gold & 1 & 2 & 2 & 2 \\
\hline Bullion & 1 & 1 & 1 & 1 \\
\hline Cascade & 10 & 14 & 14 & 13 \\
\hline Centennial & 8 & 10 & 11 & 14 \\
\hline Chinook & 4 & 4 & 4 & 4 \\
\hline Citra & $\ldots$ & $\ldots$ & $\ldots$ & 2 \\
\hline Columbia & 1 & 1 & 1 & 1 \\
\hline Crystal & 5 & 7 & 8 & 9 \\
\hline Delta & $\cdots$ & $\cdots$ & $\ldots$ & 1 \\
\hline Experimental & 2 & 2 & 1 & 1 \\
\hline Fuggle & 6 & 6 & 5 & 5 \\
\hline Golding & 2 & 2 & 2 & 3 \\
\hline Hallertau Mittelfrüh & 3 & 3 & 3 & 2 \\
\hline Liberty & 4 & 3 & 3 & 3 \\
\hline Magnum & 7 & 9 & 7 & 6 \\
\hline Meridian & 2 & 1 & 1 & $\ldots$ \\
\hline Millennium & $\ldots$ & 1 & 1 & 1 \\
\hline Mt. Hood & 2 & 3 & 3 & 3 \\
\hline Nugget & 20 & 20 & 20 & 21 \\
\hline Saaz & 1 & 1 & 1 & 1 \\
\hline Santiam & 3 & 4 & 4 & 4 \\
\hline Simcoe & $\ldots$ & 1 & 3 & 4 \\
\hline Sorachi ace & 1 & 2 & 2 & 2 \\
\hline Sterling & 5 & 7 & 7 & 8 \\
\hline Strata & $\ldots$ & $\ldots$ & 1 & 1 \\
\hline Super Galena & 3 & 1 & 1 & 1 \\
\hline Tahoma & $\cdots$ & $\cdots$ & 1 & 1 \\
\hline Tettnanger & 4 & 5 & 5 & 6 \\
\hline Willamette & 10 & 11 & 10 & 11 \\
\hline Total yards & 107 & 123 & 125 & 134 \\
\hline Yards with flag shoots $(\%)$ & $7(6.5)$ & $4(3.3)$ & $7(5.6)$ & $9(6.7)$ \\
\hline
\end{tabular}

TABLE 1. Summary of a long-term data set describing the occurrence and incidence of powdery mildew flag shoots on hop plants in commercial hop yards in Oregon and Washington ${ }^{\mathrm{z}}$

\begin{tabular}{|c|c|c|c|c|c|c|}
\hline \multirow[b]{2}{*}{ Year } & \multicolumn{3}{|c|}{ Oregon } & \multicolumn{3}{|c|}{ Washington } \\
\hline & Yards & Plants & Plants with flag shoots $(\%)$ & Yards & Plants & Plants with flag shoots $(\%)$ \\
\hline 2000 & 11 & 10,768 & $1(0.009)$ & 25 & 15,866 & $162(1.021)$ \\
\hline 2001 & 15 & 11,733 & $1(0.009)$ & 23 & 9,251 & $87(0.94)$ \\
\hline 2002 & 10 & 3,934 & $4(0.102)$ & 13 & 4,974 & $108(2.17)$ \\
\hline 2003 & 5 & 2,000 & $0(0)$ & 5 & 2,000 & $7(0.35)$ \\
\hline 2004 & 1 & 400 & $0(0)$ & 4 & 1,600 & $0(0)$ \\
\hline 2005 & 4 & 3,054 & $0(0)$ & 8 & 3,200 & $11(0.34)$ \\
\hline 2006 & 4 & 4,491 & $0(0)$ & 3 & 1,801 & $10(0.56)$ \\
\hline 2007 & 12 & 6,783 & $0(0)$ & 4 & 6,986 & $1(0.014)$ \\
\hline 2008 & 14 & 5,700 & $0(0)$ & 3 & 4,135 & $0(0)$ \\
\hline 2009 & $\ldots$ & $\ldots$ & $\ldots$ & 4 & 3,200 & $4(0.13)$ \\
\hline 2010 & 14 & 13,600 & $18(0.13)$ & 9 & 1,200 & $10(0.83)$ \\
\hline 2011 & 6 & 2,903 & $2(0.07)$ & 8 & 3,148 & $28(0.89)$ \\
\hline 2012 & 2 & 600 & $2(0.33)$ & 14 & 3,135 & $5(0.16)$ \\
\hline 2013 & 5 & 2,331 & $0(0)$ & 14 & 3,200 & $0(0)$ \\
\hline 2014 & 7 & 700 & $11(1.571)$ & 28 & 8,686 & $1(0.012)$ \\
\hline 2015 & 7 & 2,800 & $0(0)$ & 29 & 9,052 & $29(0.32)$ \\
\hline 2016 & 7 & 2,800 & $0(0)$ & 18 & 14,909 & $59(0.40)$ \\
\hline 2017 & 7 & 2,800 & $0(0)$ & 12 & 4,800 & $50(1.04)$ \\
\hline Total & 131 & 77,397 & $39(0.05)$ & 224 & 101,143 & $572(0.57)$ \\
\hline
\end{tabular}

z Number of yards included for the sample in Oregon during 2014 to 2017 is a tally only of those yards sampled using methods that were consistent with the other years (i.e., only susceptible cultivars and where levels of powdery mildew on leaves were assessed over time). 
from the ground level on each of 50 to 200 plants in a transect (row). The incidence of plants with powdery mildew was then estimated for the yard and used to calculate RAUDPC, because there were four observations collected over time from every yard. Plants were relatively small during assessments in April and May, with shoots being no more than $1 \mathrm{~m}$ in length. During June and July, plants ranged in height from approximately 2 to $6 \mathrm{~m}$ depending on cultivar, year, and farm.

Analysis of variables related to flag shoot incidence and density. Autumn and winter temperature. For the long-term data set, temperature data were obtained from the nearest regional weather station (most often the Washington State University AgWeatherNet), weather stations at regional airports, or Bureau of Reclamation AgriMet weather stations deployed in agricultural areas. The distance to the nearest station varied from less than $10 \mathrm{~m}$ to approximately $31 \mathrm{~km}$ away from yards sampled for flag shoots. Daily weather data were used to calculate mean air temperature (collected at a 1.5-m height) for each month from October to February. Soil temperature was missing from many stations and, therefore, was not considered in subsequent analyses.

Disease persistence, pesticide use, and spring pruning practices. Pesticide application records were received for 300 hop yards in the long-term data set and all yards in the intensively sampled Oregon data set. The records were examined to determine the number and timing of fungicide applications made specifically for powdery mildew, as described previously (Gent et al. 2012). Evaluation of spring pruning method and quality was done for a subset of 213 yards included in the long-term data set using a simple three-point ordinal scale (excellent, moderate, or poor), as described by Turechek et al. (2001) and Gent et al. (2012). Pruning method and quality were assessed in every yard in the intensive surveys conducted in Oregon during 2014 to 2017 using the same ordinal scale.

Associations between the incidence of powdery mildew in the previous year, current year, and flag shoot development were quantified using various approaches. In the long-term data set, preliminary analysis of variables associated with flag shoot occurrence was conducted by creating scatter plots of the incidence of plants with flag shoots with various predictor variables. For categorical variables, the distribution of flag shoots in yards was expressed in box plots to compare the distribution of flag shoots among the predictor variables. The distributions of potential risk factors for flag shoots in yards without or with flag shoots were then formally compared using the nonparametric Kolmogorov-Smirnov (K-S) test. Analyses were conducted using the NPAR1WAY procedure in SAS (version 9.4; SAS Institute, Cary, NC), with $P$ values estimated by 10,000 Monte Carlo simulation. Because there were three categories for the thoroughness of spring pruning, a linear mixed-model analysis was conducted because the $\mathrm{K}-\mathrm{S}$ is appropriate only for data with two groups. The ordinal rating of pruning quality assigned to a yard was considered to be an independent fixed factor, year was a random factor, and the incidence of plants with flag shoots was the response variable. Analyses were conducted using the GLIMMIX procedure in SAS, version 9.4.

Quantification of risk factors in intensively sampled yards in Oregon. Based on the results of the long-term data set, we explored risk factors in the intensively assessed Oregon data associated with prior occurrence of flag shoots, disease levels in the previous year, and the thoroughness of pruning. The association of these risk factors with flag shoot occurrence was again quantified using the $\mathrm{K}-\mathrm{S}$ test when testing a continuous variable and by a $\chi^{2}$ test for categorical variables.

Quantification of risk factors by Bayesian logistic regression. Candidate predictor variables were combined into a logistic regression model in a Bayesian framework, as described below. This framework was utilized because the rarity of flag shoot occurrence in the second data set created uncertainty in the interpretation of the predictions of logistic regression models constructed using frequency-based methods. In addition, the Bayesian framework allows for straightforward calculations of probability (and odds) estimates along with accompanying posterior intervals (analogous to confidence intervals). A Bayesian formulation of the logistic regression model expresses sampling and other sources of variation explicitly, which is critically important when sampling rare events. Selection of explanatory variables was conducted iteratively by examining estimated probabilities of flag shoot occurrence and examining instances where flag shoot status was misclassified. The misclassified observations were examined to identify other variables that could explain the misclassification; then, new predictor variables were created and tested again.

In the present study, a logistic regression model was fit to the dichotomous response of flag shoot presence or absence. Following standard statistical practice for notation, uppercase letters denote random variables, lowercase letters denote realizations of random variables (observed data), bold letters indicate vectors, and bold uppercase letters denote matrices of random variables. In a given yard, $Y$ was defined as a Bernoulli random variable, where $Y=1$ if a flag shoot was present and 0 otherwise. The probability of flag shoot occurrence is $\pi$, with $\operatorname{logit}(\pi)=\ln [\pi /(1-\pi)]$. Given a vector $\mathbf{x}$ of explanatory variables, the linear expression of a logistic regression equation is $\operatorname{logit}(\pi)=\boldsymbol{\alpha}+\boldsymbol{\beta}^{\prime} \mathbf{x}$, where $\boldsymbol{\alpha}$ is the intercept parameter and $\boldsymbol{\beta}^{\prime}=\left(\beta_{1}, \ldots, \beta_{\mathrm{s}}\right)$ is a vector of $s$ estimates for slope parameters. In matrix form, the probability that a flag shoot is present in a field is estimated as $\pi=\left[e^{\left(\alpha+X \beta^{\prime}\right)}\right] /\left[1+e^{\left(\alpha+X \beta^{\prime}\right)}\right]$ (Stokes et al. 2012).

In a Bayesian formulation of a statistical model, the output of an analysis is not a fixed estimate of a parameter but, rather, a posterior distribution for that parameter obtained by combining a prior distribution and a likelihood function using Bayes theorem (Gelman et al. 2014). Prior distributions may take on several forms when previous information or beliefs about the parameters exist, or the prior distribution may be "noninformative" when there is little or no previous knowledge. In such instances, selection of a noninformative prior distribution should have minimal impact on the posterior distribution. We used the R package "rstan" (R Development Core Team 2014) and the noninformative priors that are recommended for logistic regression parameters ( $t$ distributions; described on the GitHub website for rstan). Estimation of a posterior parameter distribution usually is performed using Markov Chain Monte Carlo (MCMC) methods, a general simulation method for sampling from posterior distributions to compute quantities of interest to describe the distribution. The basic premise of an MCMC approach is to create a Markov chain able to generate draws from the posterior distribution of the model parameters. Monte Carlo draws are then used to calculate statistics of interest such as, in the case of logistic regression, median values of the $\beta$ parameters and posterior intervals.

In the present analysis, four independent Markov chains with 10,000 iterations were run with dispersed starting values for the $\beta$ parameters, and the first 5,000 iterations from each chain were discarded to ensure convergence. From the 20,000 iterations that were retained, median values and $95 \%$ highest posterior density intervals for the $\beta$ parameters were calculated (Ellison 1996). Analyses were conducted using the rstan and TeachingDemos packages in R (R Development Core Team 2014).

\section{RESULTS}

Flag shoot assessments. Long-term data set. During 2000 to $2017,77,397$ plants in 131 yards were evaluated in Oregon and 101,143 plants in 224 yards were evaluated in Washington (Table 1). Flag shoots were found in a total of 15 yards in Oregon (11.4\% of yards assessed); namely, cultivars Magnum (1 yard), Nugget (1 yard), and Willamette (13 yards). The overall incidence of plants with flag shoots was $0.05 \%$. In Washington, flag shoots were found in 87 yards (38.8\% of yards assessed), including Apollo (1 yard), Bravo (6 yards), Cascade (3 yards), Columbus/Tomahawk/ 
Zeus (71 yards), Galena (1 yard), Nugget (3 yards), and Willamette ( 2 yards). The overall incidence of plants with flag shoots was $0.57 \%$ (Table 1).

Intensive assessment of flag shoots in Oregon. Flag shoots were detected in $5.5 \%$ of yards, being found in 7 of 108 yards assessed in 2014, 4 of 123 yards in 2015, 7 of 125 yards in 2016, and 9 of 134 yards in 2017. Flag shoots were found in cultivars Citra (1 yard), Delta (1 yard), Fuggle (2 yards), Hallertau Mittelfrüh (3 yards), Magnum (4 yard), Sterling (2 yards), Super Galena (4 yards), Tettnanger (4 yards), Willamette (1 yard), and Nugget (5 yards). These cultivars were present in a total of 184 of the assessments conducted in Oregon during 2014 to 2017.

Analysis of variables related to flag shoot incidence and density. Autumn and winter temperature. Mean air temperature during October to January was significantly related to the presence of flag shoots in Washington (K-S test $P=0.008,0.002,0.002$, and 0.011 for October, November, December, and January, respectively). Mean temperature was $0.15,0.79,0.78$, and $0.21^{\circ} \mathrm{C}$ higher

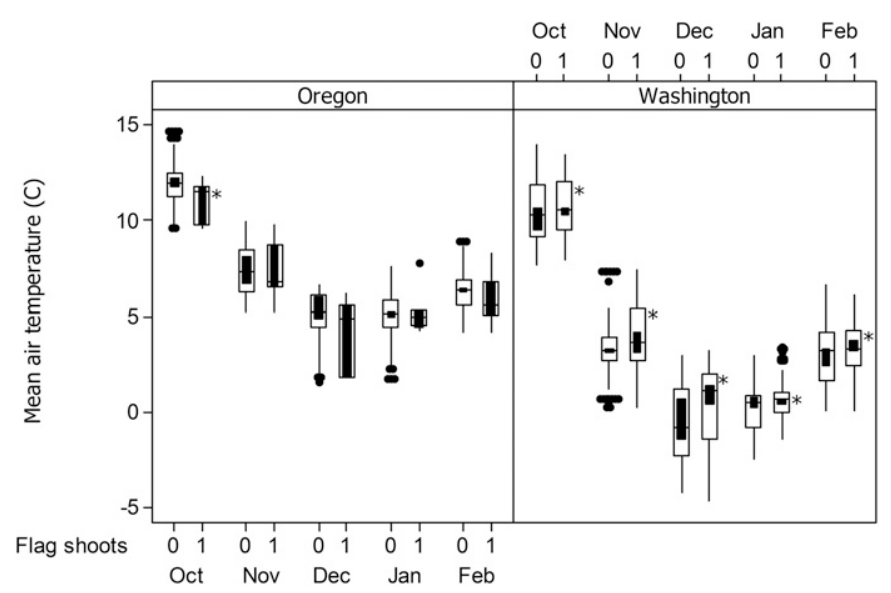

Fig. 1. Box plots showing the variability in mean daily air temperature during autumn and winter months among hop yards without (0) or with (1) powdery mildew flag shoots. Box plots show the median (line), middle $50 \%$ of the data (open box), confidence interval for the median (solid bar inside box), extremes of the data points (whiskers), and outliers (solid circles). Within a state and month, asterisk indicates a significant difference in the distribution of temperature between yards without and with flag shoots based on the nonparametric Kolmogorov-Smirnov test $(P=0.05$ as determined from a Monte Carlo simulation) in yards with flag shoots as compared with yards without flag shoots during these months, respectively (Fig. 1). In Oregon, significant differences in the distribution of temperature were detected in yards with and without flag shoots in October $(P=0.024)$ and December $(P=0.011)$ but there was no systemic relationship over time as in Washington. Furthermore, the sign of the differences in temperature was opposite in Oregon, with flag shoot occurrence associated with $0.87^{\circ} \mathrm{C}$ lower temperature in October and $1.61^{\circ} \mathrm{C}$ lower temperature in December (Fig. 1).

Disease persistence, pesticide use, and spring pruning practices. In the long-term data set, there was an association between the occurrence of flag shoots, powdery mildew levels in the previous year, powdery mildew in the current year, and the number of plants with flag shoots in the following year in Oregon $(P \leq 0.032)$ (Table 3). In yards where flag shoots were absent, on average, $9.0 \%$ of plants had powdery mildew during late June to early July in the previous year whereas, in yards where flag shoots were found, $35.3 \%$ of plants were diseased $(P=0.032)$. In turn, disease levels were greater when flag shoots were present $(31.9 \%$ of plants in late June to early July) as compared with yards where flag shoots were absent $(10.1 \%$ of plants $)(P<0.001)$. There was a small increase in the number of flag shoots found when flag shoots were present in the previous year as compared with when flag shoots were absent, increasing from $0.14 \%$ of plants to $0.18 \%(P=0.033)$.

Fungicide use patterns in the previous year were not significantly associated with flag shoot occurrence although, in the present season, yards that had flag shoots received, on average, 2.5 more fungicide applications per year as compared with yards that did not have flag shoots $(P=0.002)$ (Table 3$)$. The increased intensity of fungicide use was associated with the first application being made 21.6 days earlier in these yards $(P=0.001)$. The number of flag shoots detected in the following year was associated with the thoroughness of spring pruning $(P=0.020)$ (Table 4).

Whereas, in Oregon, there was an association between the incidence of plants with powdery mildew in the previous year and the occurrence of flag shoots, in Washington this relationship was not observed (Table 3). The incidence of plants with powdery mildew was similar in yards with and without flag shoots in both the previous and current year $(P \geq 0.050)$. There was, however, an association between the occurrence of flag shoots and the incidence of plants with flag shoots in the following season $(0.25$ versus $1.13 \%$ of plants; $P=0.003$ ). Fungicide use patterns were broadly similar in yards with and without flag shoots, with perhaps a slightly (1.7 to 3.4 days) earlier timing of the first application in yards where flag shoots were absent versus yards where flag shoots were present

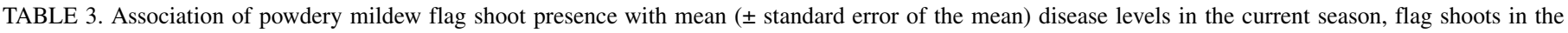
ensuing season, and grower fungicide application practices in hop yards in Oregon and Washington during 2000 to $2017 \mathrm{w}$

\begin{tabular}{|c|c|c|c|c|c|c|c|c|c|}
\hline \multirow[b]{3}{*}{ Flag shoots } & \multirow{2}{*}{\multicolumn{2}{|c|}{ Plants with powdery mildew $(\%)^{y}$}} & \multirow[b]{3}{*}{ Flag shoots next ${ }^{z}$} & \multicolumn{6}{|c|}{ Fungicide applications $(\%)^{\mathrm{x}}$} \\
\hline & & & & \multicolumn{3}{|c|}{ Previous year } & \multicolumn{3}{|c|}{ Current year } \\
\hline & Previous year & Current year & & First & Last & Total & First & Last & Total \\
\hline \multicolumn{10}{|l|}{ Oregon } \\
\hline Absent & $9.0(1.77)$ & $10.1(1.86)$ & $0.14(0.08)$ & $141.7(2.75)$ & $208.6(1.44)$ & $4.9(0.31)$ & $145.4(3.15)$ & $211.3(1.18)$ & $4.7(0.33)$ \\
\hline Present & $35.3(10.88)$ & $31.9(9.10)$ & $0.18(0.09)$ & $144.8(7.62)$ & $214.7(2.82)$ & $4.9(0.86)$ & $123.8(6.84)$ & $211.6(3.70)$ & $7.2(0.83)$ \\
\hline$P$ value & 0.032 & $<0.001$ & 0.033 & 0.419 & 0.117 & 0.410 & 0.001 & 0.340 & 0.002 \\
\hline \multicolumn{10}{|l|}{ Washington } \\
\hline Absent & $30.4(2.95)$ & $29.9(2.95)$ & $0.25(0.06)$ & $136.9(1.80)$ & $226.4(1.68)$ & $8.5(0.36)$ & $136.0(1.63)$ & $227.8(1.35)$ & $8.7(0.38)$ \\
\hline Present & $27.1(3.65)$ & $29.3(3.36)$ & $1.13(0.34)$ & $132.5(1.64)$ & $226.1(2.40)$ & $8.1(0.53)$ & $134.3(2.18)$ & $225.6(2.34)$ & $8.4(0.46)$ \\
\hline$P$ value & 0.798 & 0.050 & 0.003 & 0.042 & 0.555 & 0.787 & 0.022 & 0.579 & 0.179 \\
\hline
\end{tabular}

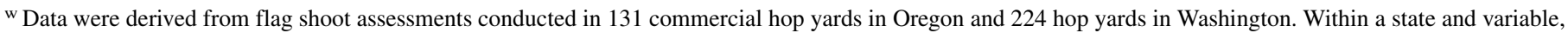

$P$ values indicate the probability values for the nonparametric Kolmogorov-Smirnov test that the distribution of the variables differ between yards where flag shoots were present or absent.

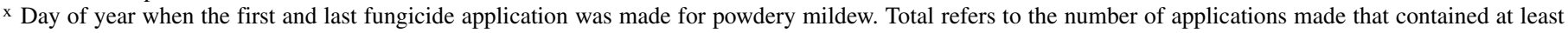
one fungicide with efficacy against powdery mildew.

y Disease ratings were conducted by inspecting the foliage on plants at a single time point during late June to early July.

z Flag shoots next year (percentage of plants). 
(Table 3). A significant effect of pruning thoroughness on the incidence of plants with flag shoots was not detected in Washington $(P \geq 0.12)$ (Table 4).

Quantification of risk factors in intensively sampled yards in Oregon. There was a strong association between the presence of flag shoots and levels of powdery mildew in the previous year $(P<$ 0.001 ) (Table 5). In yards where flag shoots were present in the previous year, on average, RAUDPC was 0.07 , whereas disease levels averaged 0.03 in yards where flag shoots were absent. In turn, there was a significant difference in the incidence of powdery mildew in the current season associated with flag shoot occurrence, with RAUDPC being 0.03 in yards without flag shoots versus 0.22 in yards with flag shoots $(P<0.001)$ (Table 5$)$. There was also evidence that the number of flag shoots in a given year was associated with whether flag shoots were present in the previous year $(P<0.001)$ (Table 5). Flag shoots were found on $0.03 \%$ of plants in yards where

TABLE 4. Association of spring pruning practices with development of foliar powdery mildew on hop (caused by Podosphaera macularis) and flag shoots ${ }^{\mathrm{Z}}$

\begin{tabular}{lll}
\hline & \multicolumn{2}{l}{ Flag shoots (percentage of plants) and SE } \\
\cline { 2 - 3 } Pruning quality & Current season & Next year \\
\hline Oregon & & \\
Excellent & $0.05(0.17) \mathrm{a}$ & $0.00(0.06) \mathrm{a}$ \\
Moderate & $0.49(0.21) \mathrm{a}$ & $0.06(0.06) \mathrm{a}$ \\
Poor & $0.14(0.21) \mathrm{a}$ & $0.27(0.08) \mathrm{b}$ \\
$P$ value & 0.187 & 0.020 \\
Washington & & \\
Excellent & $0.42(0.22) \mathrm{a}$ & $0.20(0.15) \mathrm{a}$ \\
Moderate & $0.56(0.25) \mathrm{a}$ & $0.68(0.21) \mathrm{a}$ \\
Poor & $0.78(0.24) \mathrm{a}$ & $0.25(0.20) \mathrm{a}$ \\
$P$ value & 0.177 & 0.115 \\
\hline
\end{tabular}

$\overline{\mathrm{z}}$ Within a state, means followed by a different letter indicate a significant difference in given variable in relation to pruning quality based on a mixed model analysis $(P=0.05)$. Standard errors $(\mathrm{SE})$ are presented parenthetically.

TABLE 5. Association of powdery mildew flag shoot presence with mean ( \pm standard error of the mean) disease levels in the previous year, current year, and flag shoots in the next year in 489 intensively sampled hop yards in Oregon during 2014 to 2017

\begin{tabular}{|c|c|c|c|}
\hline \multirow{2}{*}{$\begin{array}{l}\text { Flag shoot } \\
\text { occurrence }\end{array}$} & \multicolumn{2}{|c|}{$\begin{array}{l}\text { Plants with powdery } \\
\text { mildew }(\%)^{\mathrm{z}}\end{array}$} & \multirow{2}{*}{$\begin{array}{l}\text { Flag shoots next year } \\
\text { ( } \% \text { of plants })\end{array}$} \\
\hline & Previous year & Current year & \\
\hline Absent & $0.03(0.00)$ & $0.03(0.00)$ & $0.03(0.02)$ \\
\hline Present & $0.07(0.02)$ & $0.22(0.04)$ & $0.17(0.08)$ \\
\hline$P$ value & $<0.001$ & $<0.001$ & $<0.001$ \\
\hline
\end{tabular}

$\mathrm{z}$ Disease ratings were conducted monthly from April to July and used to calculate relative area under the disease progress curve. Within a variable, $P$ values indicate the probability values for the nonparametric KolmogorovSmirnov test that the distribution of the variables differed between yards where flag shoots were present or absent. flag shoots were not present in the preceding year but the incidence of plants with flag shoots was $0.17 \%$ during the next year when flag shoots were present.

Pruning method and pruning quality were associated with flag shoot occurrence. Flag shoots were found in 22 yards that were chemically pruned (18 yards) or not pruned at all (4 yards), and 5 were found in yards that were mechanically pruned (Table 6). There was not a significant association between flag shoot occurrence and pruning method before pruning $\left(\chi^{2}=0.82 ; P=0.36\right)$. However, in the yards where flag shoots were found and the yards that were later pruned, flag shoots were still present in all 18 yards after chemical pruning, whereas a flag shoot was detected in only 1 of the 5 yards after mechanical pruning. A $\chi^{2}$ test for equal proportions indicated that there were significantly fewer yards with flag shoots after pruning when pruning was conducted mechanically ( 1 of 129 yards) versus yards that were pruned chemically or left unpruned (22 of 360 yards) $\left(\chi^{2}=5.269 ; P=0.018\right)$.

Pruning quality was correlated with flag shoot occurrence. Flag shoots were found in $8.1 \%$ of yards that were rated as having poor or moderate pruning quality, whereas flag shoots were found in $1.9 \%$ of yards with excellent pruning quality $\left(\chi^{2}=7.91 ; P=0.005\right)$.

Quantification of risk factors by Bayesian logistic regression. Based on the analyses described above and iterative model fitting, three risk factors were selected and combined into a final logistic regression model. These factors were occurrence of a flag shoot in the previous year, occurrence of powdery mildew (on foliage) in the previous year, and a dichotomous variable for pruning quality (excellent versus other categories). The $95 \%$ credible intervals for the intercept parameter $\boldsymbol{\alpha}$ and the coefficients $\beta_{1}, \beta_{2}$, and $\beta_{3}$ did not include 0 (Fig. 2). From the posterior distributions, the median probability of flag shoot occurrence and the $95 \%$ posterior intervals were calculated based on all possible combinations of the three risk factors (Table 7). Note that two scenarios are not presented where flag shoots were present in the previous year but not powdery mildew, because the presence of a flag shoot by definition results in the latter. The risk of a flag shoot occurrence when no risk factors were present was 0.0008 (0.0000 to 0.0053$)$, and increased depending on the specific risk factor or risk factors present. The probability of flag shoot occurrence was 0.43 ( 0.175 to 0.709$)$ in the scenario where all three risk factors were present (Table 7).

\section{DISCUSSION}

Research progress in understanding risk factors for occurrence of powdery mildew flag shoots on hop and other plants has been slow due to the rarity of these events and volume of data needed to understand processes associated with flag shoot development. The present study has discovered several potential risk factors for flag shoot occurrence using an 18-year data set, and confirmed the importance of these risk factors in an independent census of hop yards over a 4-year period. Several important biological insights have been learned.

TABLE 6. Association of pruning method and quality with flag shoot occurrence in Oregon hop yards ${ }^{y}$

\begin{tabular}{lccccc}
\hline Pruning & Total yards & Yards with flag shoots & Yards without flag shoots & Flag shoot prevalence $(\%)$ & $\chi^{2}(P$ value $)$ \\
\hline Pruning method & & & & & \\
$\quad$ Chemical or unpruned & 360 & 22 & 338 & 6.1 & 4.0 \\
$\quad$ Mechanical & 129 & 5 & 124 & 8.1 & $0.823(0.364)$ \\
Pruning quality & 283 & 23 & 250 & 1.9 & $7.908(0.005)$ \\
$\quad \begin{array}{l}\text { Poor or moderate } \\
\text { Excellent }\end{array}$ & 206 & 4 & 202 & \\
\hline
\end{tabular}

y Data are from evaluation of 489 hop yards in Oregon during 2014 to 2017.

${ }^{\mathrm{z}}$ In mechanically pruned yards, in four instances, flag shoots were found in April before pruning occurred but were not found after pruning when assessments were repeated in May (flag shoot prevalence $=0.78 \%$ ). In chemically pruned yards, in every case, if flag shoots were found before pruning, then flag shoots also were found after the final pruning event. After pruning, there was a significant difference in flag shoot occurrence between yards that were pruned mechanically versus chemically $\left(\chi^{2}=5.629 ; P=0.018\right)$ 
Based on the long-term data set, the frequency of flag shoots in susceptible cultivars evaluated in this study was $11 \times$ greater in Washington than Oregon (Table 1). As explained previously, the yards included in this data set do not represent a probability sample from the population of hop yards but, rather, a subset of relatively susceptible cultivars and yards with a history of powdery mildew. Nonetheless, a description of this data set is potentially informative. An estimated $1.8 \%$ of plants in Washington had flag shoots during 1999 to 2002 (Mahaffee et al. 2003), whereas $0.69 \%$ of plants had flag shoots during 2000 to 2008 (Gent et al. 2008). In the current study, we found that $0.36 \%$ of plants sampled had flag shoots during 2009 to 2017. This may indicate a trend for fewer flag shoots over time in Washington, as predicted by Klein (1998), although again it is unclear whether such a trend is present in the overall population of hop yards because of the nonrandom selection of yards sampled over time.

Differences in disease pressure between Oregon and Washington, as well as within production regions in each state, were noted soon after $P$. macularis became established in the Pacific Northwestern United States (Gent et al. 2008; Mahaffee et al. 2003; Turechek et al.
2001). These differences may be explained, in part, by the greater initial inoculum density of P. macularis in Washington as compared with Oregon. The long-term flag shoot data set indicated that, in the yards sampled in Oregon, there was an association between the

TABLE 7. Posterior probability of occurrence of a powdery mildew flag shoot in hop yards in Oregon based on the presence of three risk factors

\begin{tabular}{lc}
\hline Risk factor & $\begin{array}{c}\text { Median posterior probability }(95 \% \\
\text { highest posterior density interval) }\end{array}$ \\
\hline No risk factors & $0.0008(0.0000-0.0053)$ \\
Poor pruning & $0.0065(0.0000-0.0283)$ \\
Previous disease & $0.017(0.0003-0.0515)$ \\
Previous flag shoot + previous & $0.087(0.0021-0.266)$ \\
$\quad$ disease & $0.12(0.0579-0.196)$ \\
Previous disease + poor pruning & \\
Previous flag shoot + previous & $0.43(0.175-0.709)$ \\
\hline disease + poor pruning &
\end{tabular}

z Risk factors are as described in the text. The presence of a flag shoot in the previous year is always associated with previous occurrence of disease by definition and, therefore, the two combinations of risk factors that include flag shoots in the previous year but not previous disease are not presented.

B

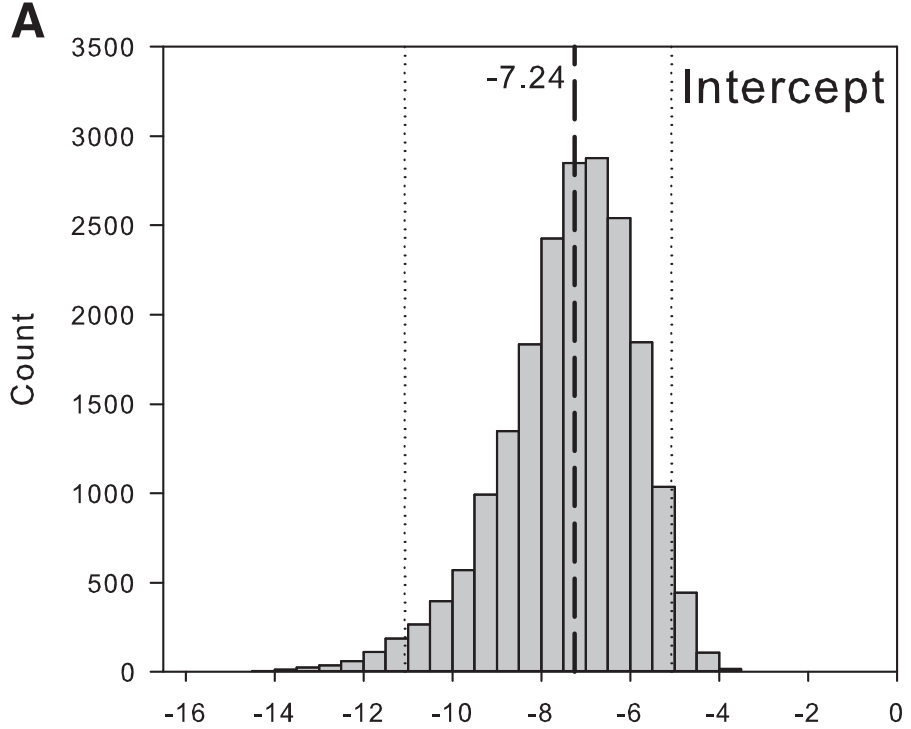

C

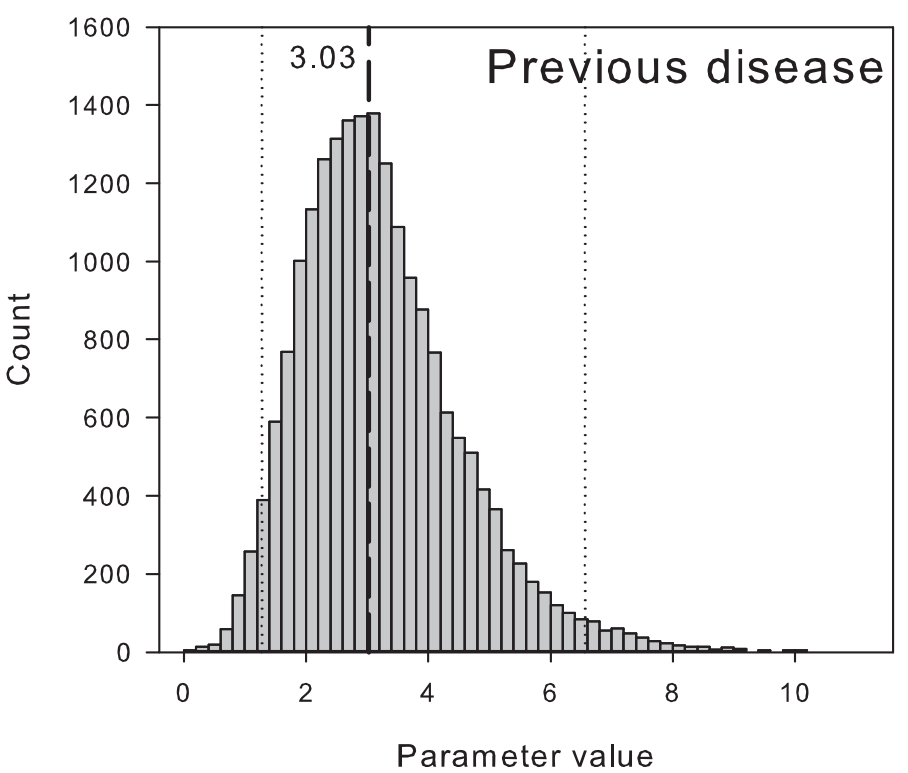

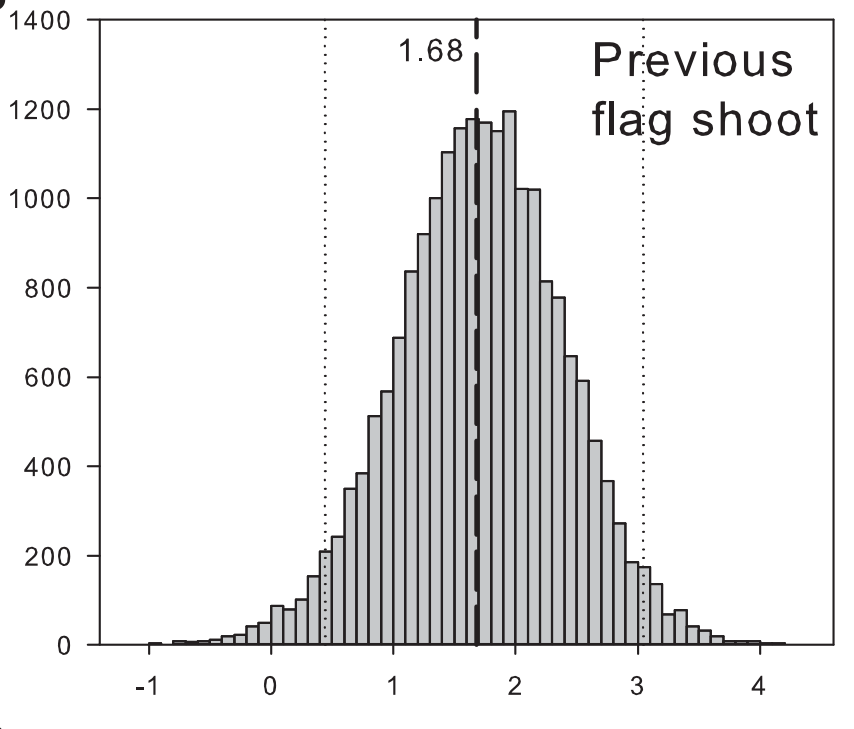

D

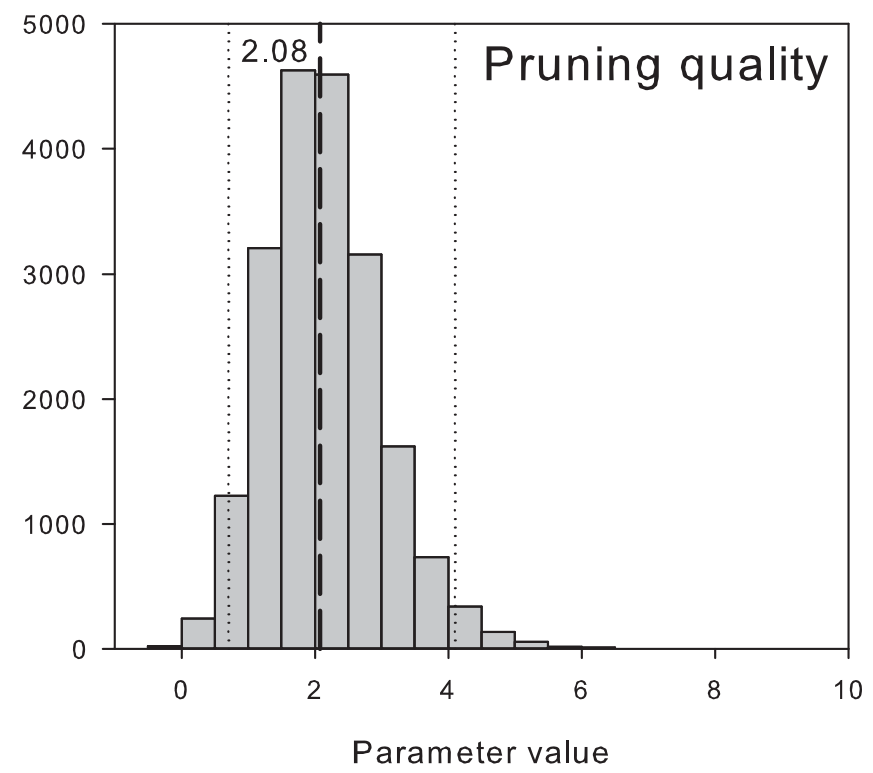

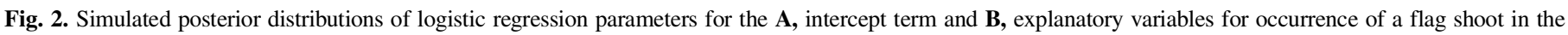

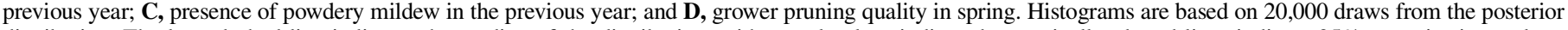
distribution. The long dashed line indicates the median of the distribution, with actual values indicated numerically; dotted lines indicate $95 \%$ posterior intervals. 
incidence of plants with powdery mildew in the previous year and subsequent occurrence of flag shoots. In turn, in both Oregon and Washington, there was evidence of reoccurrence of flag shoots in yards where flag shoots occurred in the previous year. These findings were confirmed in the intensively sampled Oregon data set as well. Similar correlations have been observed between disease severity and persistence of flag shoots in localized areas of grape vineyards (Ypema and Gubler 2000). Successful perennation of $P$. macularis in buds is influenced by the timing and severity of infection, with infection of buds near bloom (when overwintering crown buds first begin to develop) generally increasing the number of flag shoots produced (Gent et al. 2018). Thus, there appears to be a repeating cycle of high disease pressure due to overwintering inoculum dose, leading to progressively higher levels of disease during critical stages of bud development, which increases the likelihood of flag shoots in the ensuing season.

In Oregon, greater use of fungicides for powdery mildew in yards with flag shoots was associated with an earlier commencement of applications in spring. Overall disease pressure from powdery mildew tends to be lower in Oregon than in Washington, and fungicide use for management of powdery mildew usually is more frequent in Washington as compared with Oregon (Gent et al. 2017; Sherman and Gent 2014; Wolfenbarger et al. 2016). In this study, we did not find evidence that fungicide use patterns differed substantively between yards without or with flag shoots in Washington.

Field observations and experiments with potted hop plants indicate that the number of flag shoots produced may be moderated by winter temperature (Liyanage and Royle 1976). In the hop yards sampled in the long-term data set, there was an association between temperature during autumn and winter and flag shoot occurrence in Washington; associations with temperature were not consistent in Oregon. Mature hop plants produce overwintering buds both aboveground on the new wood formed in the previous year and also belowground on the root system (Rybáček 1991). Crown buds formed aboveground are those most likely to become infected by P. macularis because of their exposure to inoculum. However, because of their exposure these buds also are the most likely to be killed due to freezing (Schimming and Messersmith 1988). In other hosts, bud perennation of powdery mildew fungi is known to be temperature dependent because infected buds are less cold tolerant (Covey 1969; Pearson and Gärtel 1985; Prfece 1965; Spotts and Chen 1984). The specific observations herein are consistent with this general phenomenon. The differences observed between Oregon and Washington might also be expected given the colder winter climate of central Washington as compared with western Oregon. The median temperature during autumn and winter in Oregon was above freezing over the past 18 years (Fig. 1), suggesting that freezing events may be too infrequent to substantively influence bud mortality in the characteristically mild, maritime climate of western Oregon.

Mahaffee et al. (2003) noted a difference in the frequency of flag shoots in Washington and Oregon and suggested that mechanical pruning in spring appears to be the main reason for the differences. Using a much more extensive data set and quantitative analysis, we found an association between flag shoot occurrence and the thoroughness and method of pruning in Oregon. In the long-term data set, there was a strong association between the thoroughness of pruning (without respect to pruning method) and the incidence of flag shoots in the following year. There was an association between mechanical pruning and flag shoot occurrence that was significant only when evaluating data collected after pruning was conducted. In every case, flag shoots were found in subsequent disease assessments in yards that were chemically pruned but only in one instance in yards that were mechanically pruned. In contrast, when pruning was conducted using chemical methods, some flag shoots were detected in the following month. This finding is consistent with the observation that some proportion of infected buds may break to produce flag shoots after chemical desiccation of shoots in spring (Gent et al. 2018).
Turechek et al. (2001) suggested that the thoroughness of pruning may influence levels of powdery mildew in early spring based on a qualitative examination of a relatively small number of yards. The present analysis, which incorporates some of the data from Turechek et al. (2001) but greatly increased the spatial and temporal extent of the data set, confirmed that the thoroughness of pruning also influences the rate of flag shoot occurrence. Pruning thoroughness and pruning method are confounded, with the most thorough pruning associated with mechanical methods (Gent et al. 2012), and it is not possible to disentangle these two factors in an observational study. Pruning timing also could influence the thoroughness of pruning, especially with chemical pruning methods (Probst et al. 2016). In Washington, Probst et al. (2016) found that chemical and mechanical pruning were equally effective for controlling powdery mildew on leaves when conducted thoroughly. However, those studies were conducted in relatively small plots (approximately 45 plants per replicate plot), which is inadequate to make conclusive statements about pruning method given the rarity of flag shoot occurrence and plot-to-plot interference due to inoculum dispersal between plots. Some proportion of flag shoots can survive chemical desiccation of shoots even when this practice is conducted thoroughly (Gent et al. 2018), although this would be rare with mechanical pruning because this practice physically removes surface crown buds. Furthermore, observations from England indicate that the onset of powdery mildew became earlier with an attendant shift in cultural practices from mechanical to chemical pruning in spring (Royle 1978). Based on the observations of Royle (1978) and the results presented here, conversion to mechanical pruning should reduce the frequency of flag shoots because of both the thoroughness of this practice and because mechanical methods physically eliminate surface crown buds. Given that flag shoots may be persistent in affected yards, changes in pruning practices could have benefits that extend over multiple seasons, although these effects could be environment dependent (i.e., more effective in Oregon than Washington).

Conditions of the initial focus of disease have a strong influence on epidemic outcome with organisms characterized by longdistance dispersal (Severns et al. 2014; Xu and Ridout 1998), because the density of inoculum increases the likelihood that an organism will persist (Estep et al. 2014; Severns et al. 2015). The effectiveness of control measures is highly dependent on their timing. Field studies with the wheat stripe rust pathogen indicate that control measures that reduce epidemic rate and primary inoculum dose may need to be deployed before 1.3 generations of the fungus to affect later disease spread and development (Severns et al. 2014). In practice, then, measures that reduce primary inoculum may need to be preventative rather than reactive to effect the success of disease management, especially with polycyclic diseases where sanitation measures may only delay disease development (Madden et al. 2007). Thus, prediction of when and where primary inoculum is most likely to occur are needed to make strategic decisions on where to target management efforts for maximum effect.

With powdery mildew diseases, the risk of flag shoots from year to year can be predicted in some cases. For instance, in grape, it is more common to find flag shoots on a plant or in an area of a field that was near a flag shoot the previous year (Sall and Wrysinski 1982; Ypema and Gubler 2000). Taking three of the risk factors identified in this research, we formulated a logistic regression model in a Bayesian framework that cogently summarizes the probability of flag shoot occurrence in a format that is easily understandable. In addition to being coherent, the Bayesian framework also makes explicit the uncertainty associated with flag shoot occurrence.

Although a Bayesian framework provides a measures of uncertainty inherent in the model and accumulation of evidence (Hughes 2017), models intended to serve as decision aids often are evaluated by some means to ensure model adequacy and usefulness 
in the intended application (Altman and Royston 2000; Rykiel 1996). The logistic regression model was not validated in a strict, positivist sense with independent data (Teng 1981). However, the risk factors identified in the long-term data set were confirmed in the intensively sampled Oregon data set, which demonstrates an agreement between the modeled factors and observed phenomena. A quantitative validation ("calibration", as described by Rykiel [1996]) of the distribution of the observed logistic regression parameters (Fig. 2) would, in fact, be very costly in this instance, because calibration would require a sampling effort at least as large as the effort expended for model development. Validation of the predicted risk probabilities presented in Table 7 would be even more costly and challenging. One would need to collect data to ensure that each of the combinations of risk factors presented in Table 7 were encountered in sufficient frequency to demonstrate agreement between modeled and observed probability of flag shoot occurrence. This would be exceptionally difficult given that flag shoots occurred in only 3.3 to $6.7 \%$ of the yards in Oregon during 2014 to 2017 (Table 2). Furthermore, because flag shoots tend to persist in affected yards, one would need to identify a separate set of hop yards or conduct ratings in future years to ensure independence of the observations. These criteria make validation in a positivist sense impractical, although there are other limitations to this approach to validation as well. As Altman and Royston (2000) point out, one could collect data that demonstrated a correspondence between estimated probability of an event and the frequency of that event in a large population. This process establishes that a model satisfactorily predicts observed rates of disease in a population; however, this type of validation does not provide much certainty about whether or not an individual will become diseased. Provided that an operational threshold probability is identified for discrimination between diseased and nondiseased individuals, scoring rules and related indexes of separation can be calculated (Altman and Royston 2000; Hughes 2014; Hughes and Burnett 2017). Information content of positive and negative prediction results can be calculated for individuals that are diseased and nondiseased (Hughes 2014) and expressed graphically (Hughes et al. 2015). Nonetheless, criteria for deeming when this (or any) model is sufficiently accurate for its intended purpose remain undefined and subjective (Rykiel 1996).

The information in Table 7 may be considered a form of a decision aid that shows the risk of flag shoot occurrence given various scenarios. Importantly, two of the important risk factors for flag shoot occurrence can be known at the end of a given growing season if disease monitoring is conducted (prior occurrence of powdery mildew or a flag shoot), which provides ample time to plan and prioritize the third risk factor (spring pruning thoroughness). Of course, short-term economic constraints, logistical considerations, and other factors may trump decisions on specific conservation measures or pest management practices (Auerswald et al. 2018; Gent et al. 2013; Sherman and Gent 2014). Even so, awareness and quantification of risk as done here is a precondition for developing a landscape-level assessment of risk and an informed, coordinated disease management approach (Filho et al. 2016; Yuen and Mila 2015).

\section{ACKNOWLEDGMENTS}

We thank the many individuals who assisted with disease ratings; A. Gitelman, for assistance with aspects of the statistical analysis; M. Nelson, for his many helpful insights and assistance with this research; and G. Hughes, for providing comments that improved this article. Mention of a trademark, proprietary product, or vendor does not constitute a guarantee or warranty of the product by the USDA and does not imply its approval to the exclusion of the products or vendors that may also be suitable.

\section{LITERATURE CITED}

Altman, D. G., and Royston, P. 2000. What do we mean by validating a prognostic model? Stat. Med. 19:453-473.
Auerswald, K., Fischer, F. K., Kistler, M., Treisch, M., Maier, H., and Brandhuber, R. 2018. Behavior of farmers in regard to erosion by water as reflected by their farming practices. Sci. Total Environ. 613-614:1-9.

Barth, H. J., Klinke, C., and Schmidt, C. 1994. The Hop Atlas. Joh. Barth and Sohn, Nuremberg, Germany.

Covey, R. P. 1969. Effect of extreme cold on the overwintering of Podosphaera leucotricha. Plant Dis. Rep. 53:626-630.

Ellison, A. M. 1996. An introduction to Bayesian inference for ecological research and environmental decision-making. Ecol. Appl. 6:1036-1046.

Estep, L. K., Sackett, K. E., and Mundt, C. C. 2014. Influential disease foci in epidemics and underlying mechanisms: A field experiment and simulations. Ecol. Appl. 24:1854-1862.

Filho, A. B., Inoue-Nagata, A. K., Bassanezi, R. B., Belasque, J., Jr., Amorim, L., Macedo, M. A., Barbosa, J. C., Willocquet, L., and Savary, S. 2016. The importance of primary inoculum and area-wide disease management to crop health and food security. Food Secur. 8:221-238.

Gelman, A., Carlin, J. B., Stern, H. S., Dunson, D. B., Vehtari, A., and Rubin, D. B. 2014. Bayesian Data Analysis. CRC Press, Boca Raton, FL.

Gent, D. H., Claassen, B. J., Twomey, M. C., Wolfenbarger, S. N., and Woods, J. L. 2018. Susceptibility of hop crown buds to powdery mildew and its relation to perennation of Podosphaera macularis. Plant Dis. 102:1316-1325.

Gent, D. H., Mahaffee, W. F., McRoberts, N., and Pfender, W. F. 2013. The use and role of predictive systems in disease management. Annu. Rev. Phytopathol. 51:267-289.

Gent, D. H., Mahaffee, W. F., and Turechek, W. W. 2006. Spatial heterogeneity of the incidence of powdery mildew on hop cones. Plant Dis. 90:1433-1440.

Gent, D. H., Massie, S. T., Twomey, M. C., and Wolfenbarger, S. N. 2017. Adaptation to partial host resistance to powdery mildew in the hop cultivar Cascade by Podosphaera macularis. Plant Dis. 101:874-881.

Gent, D. H., Nelson, M. E., Gadoury, D. M., Gevens, A. J., and Hausbeck, M. K. 2015. Powdery mildew. Pages 25-29 in: Field Guide for Integrated Pest Management in Hops, 3rd ed. S. B. O'Neal, D. B. Walsh, and D. H. Gent, eds. Washington State University, Pullman.

Gent, D. H., Nelson, M. E., George, A. E., Grove, G. G., Mahaffee, W. F., Ocamb, C. M., Barbour, J. D., Peetz, A., and Turechek, W. W. 2008. A decade of hop powdery mildew in the Pacific Northwest. Online publication. Plant Health Prog. 9.

Gent, D. H., Nelson, M. E., Grove, G. G., Mahaffee, W. F., Turechek, W. W., and Woods, J. L. 2012. Association of spring pruning practices with severity of powdery mildew and downy mildew on hop. Plant Dis. 96:1343-1351.

Gent, D. H., Turechek, W. W., and Mahaffee, W. F. 2007. Sequential sampling for estimation and classification of the incidence of hop powdery mildew I: Leaf sampling. Plant Dis. 91:1002-1012.

Henning, J. A., Pethybridge, S. J., and Gent, D. H. 2009. Hop cultivars and breeding. Pages 11-14 in: Compendium of Hop Diseases and Pests. W. F. Mahaffee, S. J. Pethybridge, and D. H. Gent, eds. American Phytopathological Society Press, St. Paul, MN.

Hughes, G. 2014. Information graphs for epidemiological applications of the Kullback-Leibler divergence. Methods Inf. Med. 53:IV-VI.

Hughes, G. 2017. The evidential basis of decision making in plant disease management. Annu. Rev. Phytopathol. 55:41-59.

Hughes, G., and Burnett, F. J. 2017. Evaluation of probabilistic disease forecasts. Phytopathology 107:1136-1143.

Hughes, G., McRoberts, N., and Burnett, F. J. 2015. Information graphs for binary predictors. Phytopathology 105:9-17.

Jarvis, W. R., Gubler, W. D., and Grove, G. G. 2012. Epidemiology of powdery mildews in agricultural pathosystems. Pages 169-199 in: The Powdery Mildews, A Comprehensive Treatise. R. Belanger, W. R. Bushnell, A. J. Did, and T. L. W. Carver, eds. American Phytopathological Society Press, St. Paul, MN.

Klein, R. E. 1998. Hop powdery mildew in the Yakima Valley. Page 5 in: Proc. Tech. Commission 46th Int. Hop Congr., Yakima, WA.

Liyanage, A. de S., and Royle, D. J. 1976. Overwintering of Sphaerotheca humuli, the cause of hop powdery mildew. Ann. Appl. Biol. 83:381-394.

Madden, L. V., Hughes, G., and van den Bosch, F. 2007. The Study of Plant Disease Epidemics. American Phytopathological Society Press, St. Paul, MN.

Mahaffee, W. F., Engelhard, B., Gent, D. H., and Grove, G. G. 2009. Powdery Mildew. Pages 25-31 in: Compendium of Hop Diseases and Pests. W. M. Mahaffee, S. J. Pethybridge, and D. H. Gent, eds. American Phytopathological Society Press, St. Paul, MN.

Mahaffee, W. F., Thomas, C. S., Turechek, W. W., Ocamb, C. M., Nelson, M. E., Fox, A., and Gubler, W. D. 2003. Responding to an introduced pathogen: Podosphaera macularis (hop powdery mildew) in the Pacific Northwest. Online publication. Plant Health Prog. 4.

Mundt, C. C., and Sackett, K. E. 2012. Spatial scaling relationships for spread of disease caused by a wind-dispersed plant pathogen. Ecosphere 3:1-10.

Mundt, C. C., Wallace, L. D., Allen, T. W., Hollier, C. A., Kemerait, R. C., and Sikora, E. J. 2013. Initial epidemic area is strongly associated with the yearly extent of soybean rust spread in North America. Biol. Invasions 15:1431-1438. 
Ocamb, C., Klein, R., Barbour, J., Griesbach, J., and Mahaffee, W. 1999. First report of hop powdery mildew in the Pacific Northwest. Plant Dis. 83:1072.

Ojiambo, P. S., Gent, D. H., Mehra, L. K., Christie, D., and Magarey, R. 2017. Focus expansion and stability of the spread parameter estimate of the power law model for dispersal gradients. PeerJ 5:e3465.

Pearson, R. C., and Gärtel, W. 1985. Occurrence of hyphae in buds of grapevine. Plant Dis. 69:149-151.

Prfece, T. F. 1965. Early stages of American gooseberry mildew. Plant Pathol. 14:83-86.

Probst, C., Nelson, M. E., Grove, G. G., Twomey, M. C., and Gent, D. H. 2016. Hop powdery mildew control through alteration of spring pruning practices. Plant Dis. 100:1599-1605.

R Development Core Team. 2014. R: A Language and Environment for Statistical Computing. R Foundation for Statistical Computing, Vienna.

Royle, D. J. 1978. Powdery mildew of the hop. Pages 381-409 in: The Powdery Mildews. D. M. Spencer, ed. Academic Press, New York.

Rybáček, V., ed. 1991. Hop Production. Elsevier Science Publishing Company, New York.

Rykiel, E. J. 1996. Testing ecological models: The meaning of validation. Ecol. Modell. 90:229-244.

Sall, M. A., and Wrysinski, J. 1982. Perennation of powdery mildew in buds of grapevine. Plant Dis. 66:678-679.

Schimming, W. K., and Messersmith, C. G. 1988. Freezing resistance of overwintering buds of four perennial weeds. Weed Sci. 36:568-573.

Severns, P. M., Estep, L. K., Sackett, K. E., and Mundt, C. C. 2014. Degree of host susceptibility in the initial disease outbreak influences subsequent epidemic spread. J. Appl. Ecol. 51:1622-1630.

Severns, P. M., Sackett, K. E., and Mundt, C. C. 2015. Outbreak propagule pressure influences the landscape spread of a wind-dispersed, epidemiccausing, plant pathogen. Landsc. Ecol. 30:2111-2119.

Sherman, J., and Gent, D. H. 2014. Concepts of sustainability, motivations for pest management approaches, and implications for communicating change. Plant Dis. 98:1024-1035.
Spotts, R. A., and Chen, P. M. 1984. Cold hardiness and temperature responses of healthy and mildew-infected terminal buds of apple during dormancy. Phytopathology 74:542-544.

Stokes, M. E., Davis, C. S., and Koch, G. G. 2012. Categorical Data Analysis Using SAS, 3rd ed. SAS Institute, Cary, NC.

Teng, P. S. 1981. Validation of computer models of plant disease epidemics: A review of philosophy and methodology. Z. Pflanzenkr. Pflanzenschutz 88: 49-63.

Thomas, G. G. 1967. Hop studies by late I. H. Williams. Rep. Dep. Hop Res. Wye Coll. 1966:63-67.

Turechek, W. W., and Mahaffee, W. F. 2004. Spatial pattern analysis of hop powdery mildew in the Pacific Northwest: Implications for sampling. Phytopathology 94:1116-1128.

Turechek, W. W., Mahaffee, W. F., and Ocamb, C. M. 2001. Development of management strategies for hop powdery mildew in the Pacific Northwest. Online publication. Plant Health Prog. 2.

Wolfenbarger, S. N., Massie, S. T., Ocamb, C., Eck, E. B., Grove, G. G., Nelson, M. E., Probst, C., Twomey, M. C., and Gent, D. H. 2016. Distribution and characterization of Podosphaera macularis virulent on hop cultivars possessing R6-based resistance to powdery mildew. Plant Dis. 100: 1212-1221.

Wolfenbarger, S. N., Twomey, M. C., Gadoury, D. M., Knaus, B. J., Grünwald, N. J., and Gent, D. H. 2015. Identification and distribution of mating-type idiomorphs in populations of Podosphaera macularis and development of chasmothecia of the fungus. Plant Pathol. 64:1094-1102.

Xu, X.-M., and Ridout, M. S. 1998. Effects of initial epidemic conditions, sporulation rate, and spore dispersal gradient on the spatio-temporal dynamics of plant disease epidemics. Phytopathology 88:1000-1012.

Ypema, H. L., and Gubler, W. D. 2000. The distribution of early season grapevine shoots infected by Uncinula necator from year to year: A case study in two California vineyards. Am. J. Enol. Vitic. 51:1-6.

Yuen, J., and Mila, A. 2015. Landscape-scale disease risk quantification and prediction. Annu. Rev. Phytopathol. 53:471-484. 